\title{
Illuminating Initial Carbon-Carbon Bond Formation during the Early Stages of Methane Dehydroaromatization
}

\author{
Mustafa Çağlayan ${ }^{[a]}$, Alessandra Lucini Paioni[ ${ }^{[c]}$, Edy Abou-Hamad ${ }^{[b]}$, Genrikh Shterk ${ }^{[a]}$, Alexey \\ Pustovarenko ${ }^{[a]}$, Marc Baldus ${ }^{[c]}$, Abhishek Dutta Chowdhury*[a][d] and Jorge Gascon ${ }^{*[a]}$
}

[a] M. Çağlayan, Dr. A. D. Chowdhury, G. Shterk, A. Pustovarenko, Prof. Dr. J. Gascon KAUST Catalysis Center (KCC), Advanced Catalytic Materials King Abdullah University of Science and Technology (KAUST)

Thuwal 23955 (Saudi Arabia)

E-mail: jorge.gascon@kaust.edu.sa

[b] Dr. E. Abou-Hamad

Imaging and Characterization Department, Core Labs King Abdullah University of Science and Technology

Thuwal 23955 (Saudi Arabia)

[c] A. Lucini Paioni, Prof. Dr. M. Baldus

NMR Spectroscopy group, Bijvoet Centre for Biomolecular Research

Utrecht University

Padualaan 8, $3584 \mathrm{CH}$ Utrecht (The Netherlands)

[d] Dr. A. D. Chowdhury

The Institute for Advanced Studies (IAS)

Wuhan University

Wuhan 430072, Hubei (China)

E-mail: abhishek@whu.edu.cn

Supporting information for this article is given via a link at the end of the document.

\begin{abstract}
Still in 2020, methane dehydroaromatization (MDA) is among the most challenging processes in catalysis science due to the inherent harsh reaction conditions and fast catalyst deactivation. To improve it further, understanding the initial C-C bond formation mechanism is sine qua non. However, consensus about the actual reaction mechanism is still to be achieved. In this work, using advanced magic angle spinning (MAS) solid-state NMR spectroscopy, we study in detail the early stages of the reaction over a welldispersed Mo/H-ZSM-5 catalyst. Simultaneous detection of acetylene (i.e., presumably the direct $\mathrm{C}-\mathrm{C}$ bond forming product from methane), methylidene, allenes, acetal and surface-formate species along with the typical olefinic/aromatic species allow us to conclude the existence of two independent $\mathrm{C}-\mathrm{H}$ activation pathways. Moreover, this study emphasizes the significance of mobility-dependent host-guest chemistry between inorganic zeolite and its organic trapped species during heterogeneous catalysis.
\end{abstract}

The direct conversion of methane, the main component of natural gas and a byproduct of oil refining, into more value-added liquid fuels and chemicals, keeps attracting a great deal of attention. Although the non-oxidative methane dehydroaromatization (MDA) was first reported on Mo loaded ZSM-5 catalyst by Wang et al. in $1993^{[1]}$, it is still an attractive research field, not only due to its inherent challenges with respect to the initial $\mathrm{C}-\mathrm{H}$ bond activation (first bond dissociation energy: $439.3 \mathrm{~kJ} / \mathrm{mol}$ ) ${ }^{[2]}$, but also its reaction mechanism and the exact role of the popular MoZSM- 5 catalysts are yet to achieve consensus within the scientific community. Since the success of Mo/ZSM-5 system, several different metals (W, Fe, V, Cr etc.) and supports (ZSM-8, MCM22, TNU-9 etc.) have already been screened. ${ }^{[3,4]}$ However, none of these catalysts has been able to overcome the inevitable deactivation due to coking. Therefore; the understanding of reaction mechanism, particularly during the early/induction period, of this potential industrially relevant reaction should be prioritized, as such information often plays a critical role to upgrade both catalysts and the process itself. ${ }^{[5,6]}$

Based on the growing agreement, active Mo species for methane activation are originated from mostly monomeric and/or dimeric $\mathrm{Mo}_{x} \mathrm{O}_{y}$ complexes attached to the bridging oxygens of the zeolite, especially the ones between framework $\mathrm{Al}^{3+}$ and $\mathrm{Si}^{4+} \cdot{ }^{7-9]}$ However; a strong debate (Section S2.1) about the structure of active Mo sites $\left(\mathrm{MoO}_{x} \mathrm{C}_{y}, \mathrm{Mo}_{\mathrm{x}} \mathrm{C}_{\mathrm{y}}\right.$ etc.), location (pore surface vs. external surface) and their role in the reaction mechanism is still to be resolved. ${ }^{[10-15]}$ Besides the ongoing debates regarding the active sites, gaining insight into the initial $\mathrm{C}-\mathrm{C}$ bond formation mechanism and further oligomerization-cyclization of the intermediates is critical. In many earlier studies, Mo sites and Brønsted acid sites (BAS) of ZSM-5 were considered as two 'independent' reaction centers. ${ }^{[16-21]}$ Herein, active molybdenum

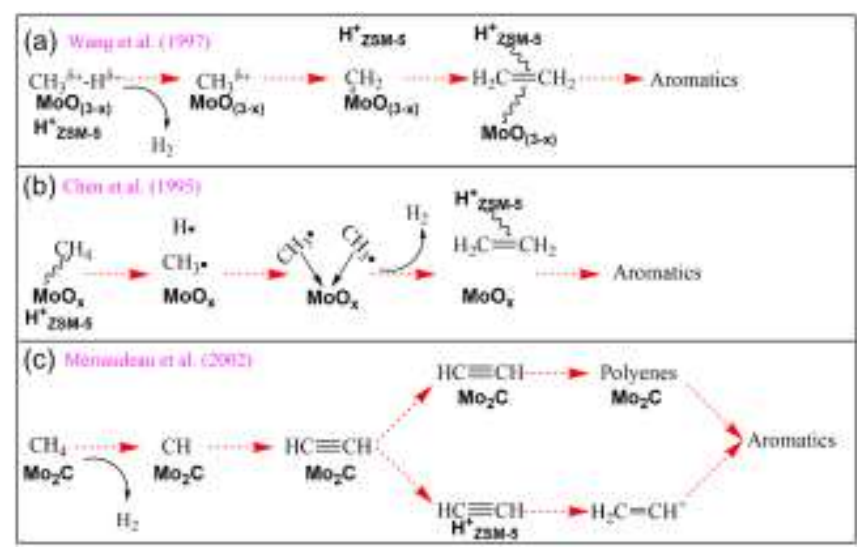

Scheme 1. MDA mechanisms proposed by (a) Wang et al. ${ }^{[20]}$, (b) Chen et al. ${ }^{[17]}$ and (c) Mériaudeau et al. ${ }^{[23]}$ 
sites would form ethylene that would be further oligomerizedcyclized to aromatics on BAS. Wang et al. ${ }^{[1,20]}$ proposed that $\mathrm{CH}_{4}$ is polarized $\left(\mathrm{CH}_{3}{ }^{\delta+}-\mathrm{H}^{\delta-}\right)$ by partially reduced $\mathrm{MoO}_{(3-\mathrm{x})}$ forming a carbene-like " $\mathrm{CH}_{2}=\mathrm{MoO}_{(3-x)}$ " species, which led to ethylene (Scheme 1a) However; Chen et al. ${ }^{[17]}$ suggested that methane activation occurs with the formation of free $\mathrm{CH}_{3}$. radicals formed at the interphase of $\mathrm{MoO}_{x}$ and BAS (Scheme 1b). Then, the system proceeds with dehydrodimerization of the methyl radicals and aromatization of the ethylene produced. In contrast to the abovementioned mechanisms based on bifunctionality in which ethylene is the main intermediate, Mériaudeau et al. proposed an alternative 'acetylene-based' monofunctional mechanism (Scheme 1c). ${ }^{[22,23]}$ Initially they detected low-concentrations of acetylene (compared to ethylene) that increased upon reducing contact time. ${ }^{[22]}$ In light of these results, the following two mechanisms were proposed: (i) a monofunctional pathway, where acetylene, the main intermediate, is oligomerized on molybdenum sites $\left(\mathrm{Mo}_{2} \mathrm{C}\right)$ into polyene and cyclized into aromatics; and (ii) a bifunctional pathway, where acetylene (and possibly ethylene also) form high-weight polyenes through vinyl cations $\left(\mathrm{C}_{2} \mathrm{H}_{3}{ }^{+}\right)$on BAS. ${ }^{[23]}$ The latter pathway was considered as extremely fast and requires free acid sites. However, the spectroscopic identification on both solid-state (i.e., zeolite-trapped) and gas-phase of any abovementioned intermediates has not been achieved yet. In recent literature as well, the mechanism is still ambiguous. In 2018, Kosinov and his colleagues ${ }^{[11]}$ brought a new perspective to the induction period first defined by Rosynek et al. ${ }^{[18]}$ by distinguishing it from the reduction of Mo species. After the formation of active Mo sites, they observed a buildup of hydrocarbon species inside the pores and proposed that these confined polyaromatic molecules have a similar role to that of the organocatalytic intermediates found in the well-known methanolto-hydrocarbon (MTH) reactions. Vollmer et al. also investigated the mechanism with ${ }^{13} \mathrm{CH}_{4}$ after showing the active molybdenum site formation without any coke via CO treatment. ${ }^{[12,24]}$ They observed the incorporation of carbidic carbons in Mo sites into the products (i.e. benzene) and stated that it is very similar to the role of oxygen in the Mars-Van-Krevelen mechanism. Moreover; in a recent study, Vollmer and her colleagues stated that $\mathrm{C}_{2} \mathrm{H}_{4}$ is likely not being the main intermediate of MDA. ${ }^{[25]}$ Therefore, the nature of the formation of the first C-C bond containing species, is still unclear and ambiguous. With the aim to illuminate this issue, herein, we establish a fundamental understanding on the early stages of DHA reaction; primarily through the identification of numerous reactive intermediates (acetylene, surface-formate, acetal, allene etc.) as well as mono- and bi-functionality of the catalytic materials. As a result, the 'mobility-dependent' hostguest chemistry between Mo-ZSM-5 and its trapped organics has also been evaluated.

In the first phase of our study, to prevent the formation of molybdenum clusters, we prepared a Mo loading of ca. 2 wt. \% on a nano-sized ZSM-5. The characterization of the fresh catalyst (Raman, XRD, $\mathrm{N}_{2}$ physisorption and TEM-EDX mapping) proved the good dispersion of Mo (see Section S2.2). In Figure 1, the performance of the catalyst under non-oxidative conditions is shown. As it can be clearly observed (Figure 1a-b); during the initial two GC injections, a low total product yield accompanied by the high formation rate of $\mathrm{CO}$ and $\mathrm{H}_{2}$ indicate the reduction of $\mathrm{Mo}$ sites and activation of the catalyst. Although $\mathrm{CO}$ formation after the initial Mo reduction period decreases significantly; it continues in low amounts during the whole process. $\mathrm{CO}_{2}$ was also detected
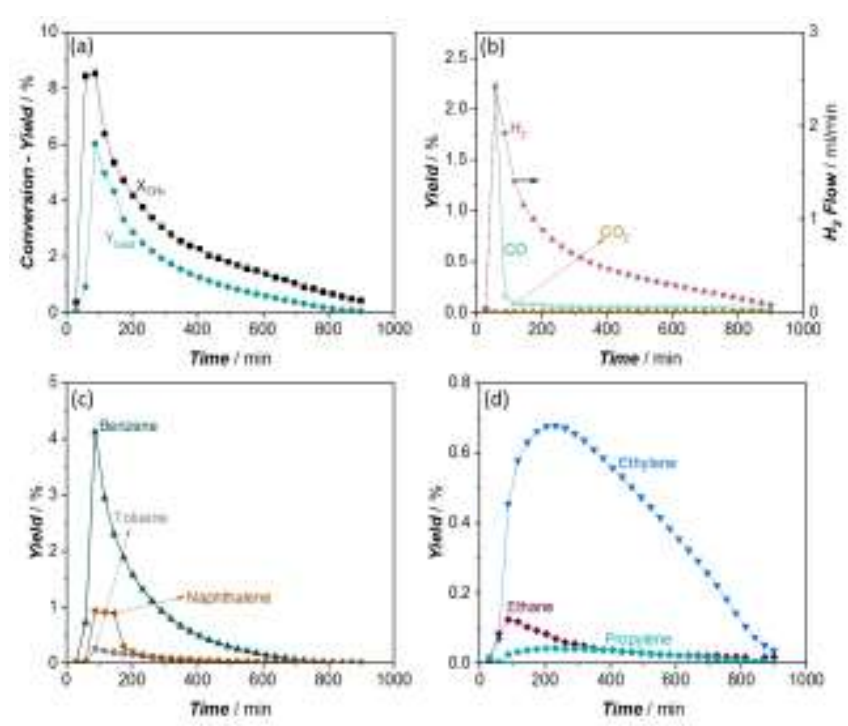

Figure 1. Catalytic activity of 2 wt $\% \mathrm{Mo} / \mathrm{H}-\mathrm{ZSM}-5$ at $725^{\circ} \mathrm{C}$ under non-oxidative conditions (11.765 mol\% $\mathrm{N}_{2}$ and $88.235 \mathrm{~mol}^{2} \mathrm{CH}_{4}$ in the inlet, WHSV: $2.58 \mathrm{~h}^{-1}$ ) (a) Conversion and Total Yield (without $\mathrm{CO}$ and $\mathrm{CO}_{2}$ ), (b) Yields of $\mathrm{CO}, \mathrm{CO}_{2}$ and $\mathrm{H}_{2}$ Flow (c) Yields of major aromatic products, (d) Yields of major aliphatic products

but only at the beginning and in a very small amounts $\left(Y_{\mathrm{CO} 2}=\right.$ $0.03 \%$ in the first injection). After this period, the typical MDA activity of Mo/ZSM-5 catalyst is observed. Total product yield $\left(Y_{\text {total }}\right)$ and conversion $\left(X_{\mathrm{CH}_{4}}\right)$ reach maximum values and then decay with time. In Figure $1 \mathrm{c}$ and $\mathrm{d}$, the dominant aromatic and aliphatic products in the outlet stream are presented. As expected, the major contribution to total product yields comes from the aromatics. When the catalytic system reaches the maximum hydrocarbon yield (not including $\mathrm{CO}$ and $\mathrm{CO}_{2}$ ), some of the major products (i.e. benzene, toluene, naphthalene, ethane) also reach their peak values. However; products like ethylene, propylene, 1 butene (Figure S8b) and o-xylene (Figure S8c) show their maximum production rate after the maximum total product yield. More details about the synthesis, characterization of the fresh/spent catalyst, and catalysis can be found in the Supporting Information.

In the next-phase of our study, in order to provide more in-depth mechanistic information, advanced magic angle spinning (MAS) solid-state NMR spectroscopy was performed on post-reacted 2 wt. \% Mo/H-ZSM-5 material after the MDA reaction at $725{ }^{\circ} \mathrm{C}$ using fully ${ }^{13} \mathrm{C}$-enriched methane $\left({ }^{13} \mathrm{CH}_{4}\right)$ as reactant (Figures 23, Section S2.5-S2.6 and Figures S11-S19 in the ESI). We prepared two sets of samples, after $50 \mathrm{~min}$ and 2 hours of reaction time, i.e., (i) MoZSM5_50 min, and (ii) MoZSM5_2 hr, to identify the catalytically influential species during the early stages of reaction by multidimensional solid-state NMR correlation experiments. The ${ }^{1} \mathrm{H}^{13} \mathrm{C}$ cross-polarization $(\mathrm{CP})^{[26]},{ }^{1} \mathrm{H}-{ }^{13} \mathrm{C}$ insensitive nuclei enhanced by polarization transfer (INEPT) ${ }^{[27]}$, and ${ }^{13} \mathrm{C}$ direct excitation (DE) solid-state NMR spectra of the spent catalyst are presented in Figure S11. In general, the following four features were primarily observed in the $1 \mathrm{D}{ }^{13} \mathrm{C}$ spectra: (i) $-5--10$ ppm zeolite trapped multiple adsorbed forms of unreacted methane, (ii) 20-52 ppm aliphatic moieties (e.g. 


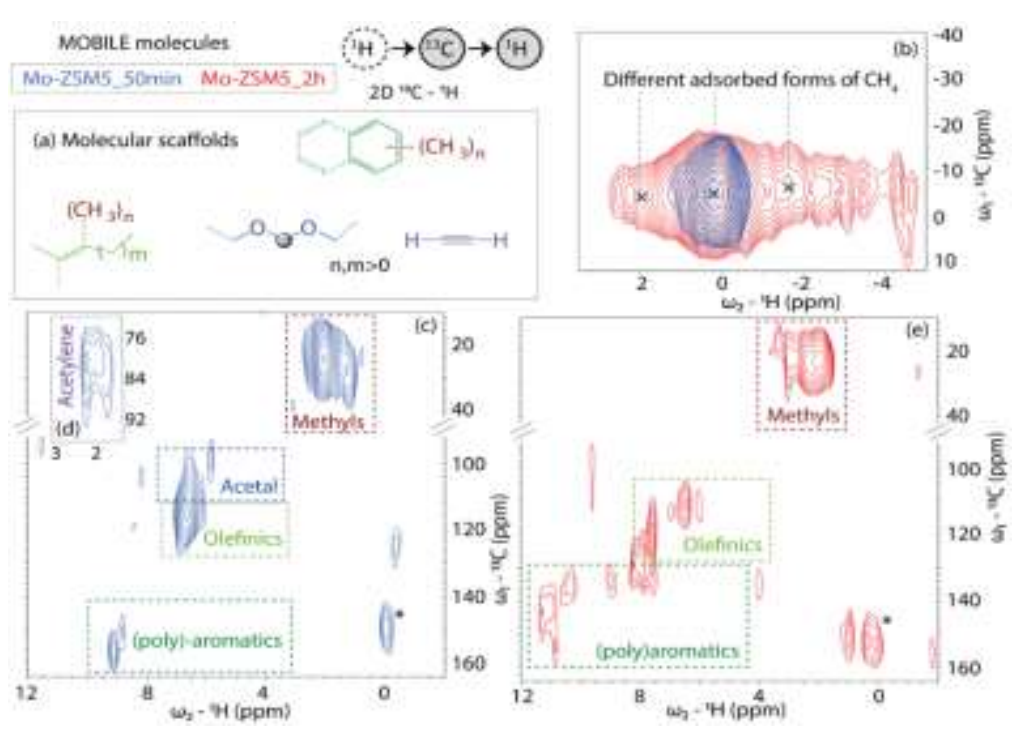

Figure 2. Identification of post-reacted Mo/H-ZSM-5 zeolite-trapped mobile molecules in Jcoupling based 2D MAS solid-state NMR ${ }^{13} \mathrm{C}-{ }^{-1} \mathrm{H}$ correlations experiment(s) $\left({ }^{*}\right.$ :spinning side bands). The spectra were obtained after $\left({ }^{13} \mathrm{C}\right.$-)methane dehydroaromatization reaction over Mo-ZSM- 5 at $725^{\circ} \mathrm{C}$ for $50 \mathrm{~min}$ (in blue) and 2 hour (in red): (a) identified molecular keys, zooms of (b) different adsorbed forms of methane, (c) alkylated unsaturated hydrocarbon (olefins/aromatics) regions, including acetal and (d) acetylene/alkyne (in 50 min sample only) as well as (e) alkylated unsaturated hydrocarbon (olefins/aromatics) regions in 2 hour sample. The respective full-range spectra, as well as experimental details, were included in the supporting information.

alkyl/methoxy groups), (iii) 110-150 ppm aromatic/olefinic groups, and (iv) $170-175$ ppm surface-formate species.

A complementary set of solid-state NMR magnetization transfer sequences was deliberately employed for the spectral separation of zeolite-trapped species based on mobility. ${ }^{[28-30]}$ This strategy, that was originally developed for the analysis of biomolecules, ${ }^{[31,32]}$ has recently gained attention in the elucidation of reaction mechanisms in zeolite-chemistry and to evaluate hostguest chemistry. As a result, we could independently distinguish both mobile (i.e., with fast tumbling) and rigid (i.e.,chemisorbed) versions of zeolite-trapped organics (cf. Figure S11). Such spectral separation of mobile and rigid species is possible by invoking through-bond (scalar interactions such as in INEPT) ${ }^{[27]}$ and through-space (dipolar transfer such as in $\mathrm{CP})^{[26]}$ magnetization transfer sequences, respectively. For instance, through-bond mediated magnetization transfer schemes will be able to detect molecules that exhibit fast overall tumbling or contain locally mobile groups, such as seen in methyl groups that display fast rotation around the $\mathrm{C}-\mathrm{C}$ axis (see the individual INEPT spectrum in Figure S11). Similarly, the (CP-like) dipolar-based magnetization transfer mechanisms primarily could detect either immobilized/rigid (such as physisorbed in or on the catalyst material) or limited mobility (such as in the case of a molecule trapped within the zeolite structures) species. Notably, all chemical species (irrespective of mobility) could be identified using direct excitation experiments.

In the solid-state NMR spectra probing mobile molecules (Figure 2, see also Figure S13 \& S17), signals corresponding to multiple adsorbed forms of unreacted methane were readily identified in the upfield region (Figure 2b). ${ }^{[33-37]}$ However, the predominant zeolite-trapped hydrocarbon species are (expectedly) unsaturated in nature, such as alkylated olefinic/(poly)aromatic species (Figure 2c-e). For example in ${ }^{13} \mathrm{C}-{ }^{-1} \mathrm{H}$ correlation experiments, the resonances at $\sim 121\left({ }^{13} \mathrm{C}\right) / \sim 7.6\left({ }^{1} \mathrm{H}\right) \mathrm{ppm}$ and $\sim 129$ $\left({ }^{13} \mathrm{C}\right) / \sim 8\left({ }^{1} \mathrm{H}\right)$ ppm in MoZSM5_2hr sample could be attributed to olefinic and aromatic species, respectively (Figure 2e). ${ }^{\left[{ }^{29]}\right.}$ Moreover, in the MoZSM5 50 sample, the cross-peaks between $\sim 81\left({ }^{13} \mathrm{C}\right)$ and $\sim 2\left({ }^{1} \mathrm{H}\right)$ ppm are possibly the most significant observation in this work, which is a characteristic spectroscopic signature of acetylene (Figure 2d). ${ }^{[38]}$ Acetylene has long been hypothesized in MDA reaction as the most influential direct $\mathrm{C}-\mathrm{C}$ bond containing intermediate from methane, ${ }^{[22,23]}$ but its spectroscopic detection was elusive till now. Not only on solid-state, acetylenes have also been detected in the gas-phase (along with other alkenes and allenes), through cold-trapping control experiments (Section S2.6 \& Figure S20-21). ${ }^{[39]}$ The slight downfield nature of signals could be attributed to the bi-functional nature of the zeolite environment, which is also paramagnetic in nature. ${ }^{[40]}$ In addition, two more important oxygenate-based intermediates have been identified particularly in the MoZSM5_50 sample: (i) acetal $\left(\sim 104\left({ }^{13} \mathrm{C}\right)\right.$ and $\sim 6.5\left({ }^{1} \mathrm{H}\right) \mathrm{ppm}$ in Figure $2 \mathrm{c}^{[28,41]}$ and (ii) surface-formate $\left(\sim 174\left({ }^{13} \mathrm{C}\right)\right.$ and $\sim 10$ $\left({ }^{1} \mathrm{H}\right) \mathrm{ppm}$ in Figure S13a) species. ${ }^{[28,42]}$

To probe rigid/immobilized molecules, both $2 \mathrm{D}{ }^{13} \mathrm{C}-{ }^{1} \mathrm{H}$ and ${ }^{13} \mathrm{C}-$ ${ }^{13} \mathrm{C}$ dipolar-based correlation spectra were acquired (Figure 3 , see also Figure S12, S14-S16, S18-S19). Characteristically, rigid species are very similar to their mobile counterparts (Figure 3a). Again, the multiple rigid-version of adsorbed unreacted methane was identified (Figure 3a). ${ }^{[33-37]}$ The presence of numerous zeolite-trapped alkylated olefinic/(poly)aromatic species were also detected through both $2 \mathrm{D}{ }^{13} \mathrm{C}-{ }^{-1} \mathrm{H}$ (Figure 3c,e) correlations, which is consistent with our GC analysis as well. Interestingly, a higher degree of alkylation was observed among rigid molecules

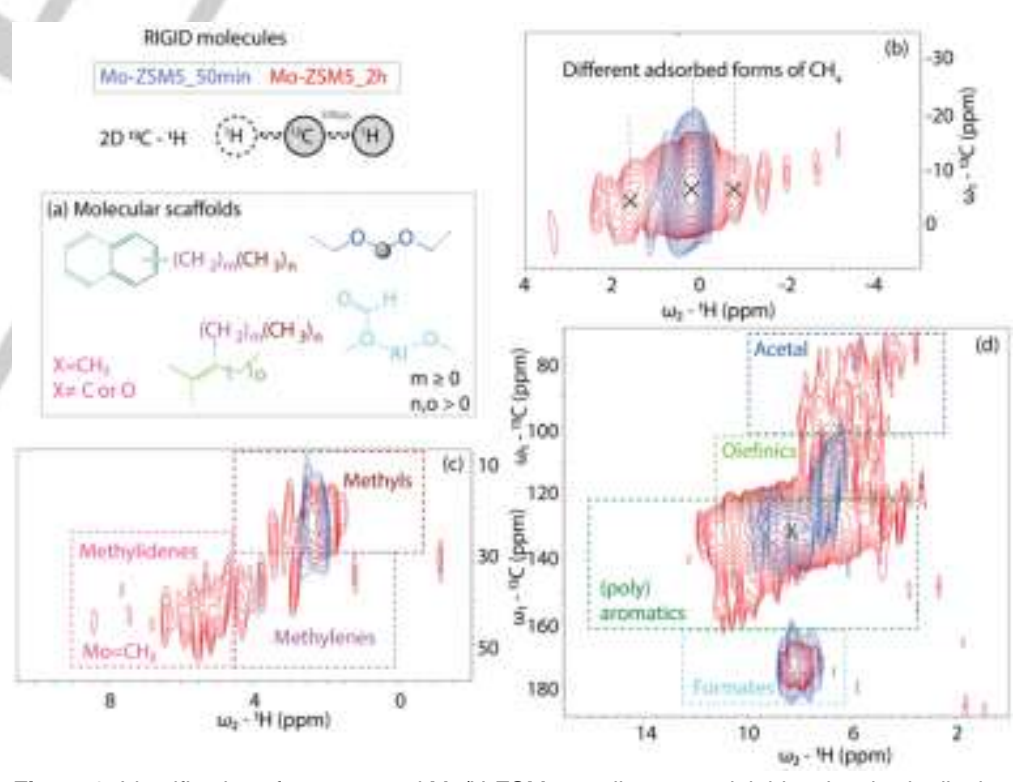

Figure 3. Identification of post-reacted Mo/H-ZSM-5 zeolite-trapped rigid molecules in dipolarcoupling based 2D MAS solid-state NMR ${ }^{13} \mathrm{C}-{ }^{1} \mathrm{H}$ correlation experiments. The spectra were obtained after $\left({ }^{13} \mathrm{C}\right.$-) methane dehydroaromatization reaction over Mo-ZSM- 5 at $725^{\circ} \mathrm{C}$ under dry conditions for $50 \mathrm{~min}$ (in blue) and 2 hour (in red): (a) identified molecular keys, zooms of (b) different adsorbed forms of methane, (c) degree of alkylation (methyl/ methylene/methylidene groups), as well as (d) alkylated unsaturated hydrocarbon (olefins/aromatics) regions, acetal and formate species. The respective full-range spectra, as well as experimental details, were included in the supporting information. 
compared to their mobile counterparts, as both methylene $\left(-\mathrm{CH}_{2}-\right.$, e.g., $\sim 36\left({ }^{13} \mathrm{C}\right)$ and $\sim 2.8\left({ }^{1} \mathrm{H}\right)$ ppm in MoZSM5_2hr sample) and methyl groups were individually distinguishable (Figure 3c). ${ }^{[29]}$ Contrary, only methyl groups were observed among mobile molecules (Figure 2c,e). Interestingly, methylene signals were only visible after 2 hours, which indicates a progression of the degree of alkylation during the reaction. Moreover, a few methylene-based rigid spin systems have correlations between $\sim 42-45 \mathrm{ppm}\left({ }^{13} \mathrm{C}\right)$ and $~ 5-$ 6 ppm $\left({ }^{1} \mathrm{H}\right)$, which could be attributed to methylidene groups $\left(\mathrm{CH}_{2}=\mathrm{X}, \mathrm{X} \neq \mathrm{C}\right.$ or $\mathrm{O}$, see Figure $\left.3 \mathrm{c}\right)$. Herein, we hypothesize that such methylidene groups should be attached to $\mathrm{Mo}$, inducing carbene character on the catalyst $\left(\mathrm{Mo}=\mathrm{CH}_{2}\right)$, and could be treated as a precursor of the well-known molybdenum carbide species. It should be mentioned that similar " $\mathrm{Mo}=\mathrm{CH}_{2}$ " groups are recognized as the active sites during Mo/W-zeolite catalysed metathesis reactions. ${ }^{[43-45]}$

Next, both rigid-version of acetals and surface-formate species (Figure 3e) were identified. Overall, signals of rigid molecules have always demonstrated more than one peak for the same resonance, which means that the same molecule exists in different molecular environments inside the zeolite framework, i.e., heterogeneity in the molecular environment of the entrapped species. This same observation was also observed for unreacted methane (Figure $2 b \& 3 b$ ), as its multiple adsorbed forms were identified too and hence, further advocates for the local heterogeneity within the material. The existence of surfaceformate species, i.e., the ${ }^{13} \mathrm{C}$ correlations observed at $170-173$ ppm correlating with a ${ }^{1} \mathrm{H}$-signal at $\sim 8 \mathrm{ppm}$ (Figure $3 \mathrm{e}$ ), is indicative of the occurrence of $\mathrm{CO}$-insertion ${ }^{[46-51]}$, which is known to generate hydrocarbon pool species during the zeolitecatalysed MTH process (vide-infra). ${ }^{[28,41,42]}$ However, it should also be mentioned that these species can only be formed in the very early stages of the reaction making use of $O$ present in the zeolite and metal oxide Mo precursor (cf. Figure 1b). ${ }^{[11,12,24]}$

On the basis of the above-mentioned results, different reaction pathways for the MDA process are proposed in Scheme 2. Due to the controversial status of the MDA reaction mechanism, we have only considered the concrete experimental/spectroscopic evidence observed in this work to construct this mechanistic overview, particularly during early stages of reaction. Although it has been long hypothesized that the reaction mechanisms of both MTH and MDA processes have similarities, ${ }^{[11]}$ the extent of resembles has never properly been illustrated. Our study reveals that the at-least two $\mathrm{C}-\mathrm{H}$ activation pathways were simultaneously operational during the initial period of MDA reaction; one of them has a conceptual resemblance with the MTH reaction mechanism. In our work, three distinct and significant findings (compared to the current state-of-the-art) are the spectroscopic identification of surface-formate species, and Mo-methylidene as well as acetylene, which could easily be correlated with bi- and monofunctionality of the catalytic material, respectively. ${ }^{[10]}$

Almost two decades ago, Mériaudeau et al. first proposed activation of methane to acetylene, and followed by aromatization over Mocarbide into benzene. ${ }^{[22,23]}$ In this work, the spectral identification of acetylene provides support to their proposal. Hence, in this route, bifunctionality is not a pre-requisite criterion, as the Mo-methylidene could be the precursor of Mocarbide (pathway a in Scheme 2). ${ }^{[52,53]}$ Simultaneously, it is important to recognize that methane activation upon molybdenum is also associated with deoxygenation (XPS spectrum of spent catalyst Figure S5b, and additional discussion in Section S2.3), which eventually leads to the formation of $\mathrm{CO}$ (Figure 1b) during the process. The Brønsted acid sites of zeolite then undergo CO-insertion to form the corresponding surface-formate species, which then lead to the formation of acetal upon nucleophilic attack from the in-situ formed surface-methoxy species (pathway b in Scheme 2). ${ }^{[28,41]}$ All three key intermediates, i.e., surface-formate, surfacemethoxy, and acetal, were experimentally verified in this work (Figures 2,3). Unlike in the acetylene/methylidene-route, bifunctionality is a mandatory criterion in the carbonyl-route (pathway b in Scheme 2). The later route is indeed analogous to MTH chemistry and extensively verified by both spectroscopic and theoretical means in recent times..$^{[6,28,29,54-56]}$ Finally, all these intermediates lead to the formation of the classical hydrocarbon pool (HCP) type mechanism during the auto-catalytic period of the reaction. Similar to MTH catalysis on ZSM-5, hydrocabons trapped in the framework affect the unit cell dimensions, so the difference between the lengths of $a$ - and $b$ - vectors decreases with deactivation (XRD refinement analysis in Section S2.32.4). ${ }^{[57]}$

In summary; beyond identifying initial C-C bond containing reactive intermediates not mentioned before in MDA literature and initial $\mathrm{C}-\mathrm{H}$ activation pathways during the early stages of reaction, probably the most prominent outcome of this work is the utilization of 'mobility-dependent' advanced MAS solid-state NMR spectroscopic methodologies to unravel the nature of zeolitetrapped organic species during MDA. This information is extremely difficult to obtain by operando techniques (or other spectroscopic/analytic means) due to the harsh reaction conditions inherent to MDA process. We anticipate that such precise information would allow the catalysis community to develop technologically and economically viable MDA processes in the near future. In a broader perspective, this work also highlights the significance of host-guest chemistry during zeolitecatalyzed hydrocarbon conversions. 


\section{Acknowledgements}

Funding for this work was provided by King Abdullah University of Science and Technology (KAUST). ADC also thanks the starting grant support from IAS, Wuhan University. ALP was supported by a TOP - PUNT grant (no. 718.015.001) to M.B. from Netherlands Organization of Scientific Research (NWO).

Keywords: methane dehydroaromatization - reaction mechanism $\bullet$ zeolites $\cdot$ solid-state NMR $\bullet$ bifunctional catalyst

[1] L. Wang, L. Tao, M. Xie, G. Xu, J. Huang, Y. Xu, Catal. Letters 1993, 21, 35-41.

[2] I. Vollmer, I. Yarulina, F. Kapteijn, J. Gascon, ChemCatChem 2019, 11, 39-52.

[3] S. Ma, X. Guo, L. Zhao, S. Scott, X. Bao, J. Energy Chem. 2013, 22 $1-20$.

[4] B. M. Weckhuysen, D. Wang, M. P. Rosynek, J. H. Lunsford, J. Catal. 1998, 175, 347-351.

[5] E. M. Gallego, M. T. Portilla, C. Paris, A. León-Escamilla, M. Boronat, M. Moliner, A. Corma, Science (80-. ). 2017, 355, 1051-1054.

[6] I. Yarulina, A. D. Chowdhury, F. Meirer, B. M. Weckhuysen, J. Gascon, Nat. Catal. 2018, 1, 398-411.

[7] J. Gao, Y. Zheng, J. M. Jehng, Y. Tang, I. E. Wachs, S. G. Podkolzin Science (80-. ). 2015, 348, 686-690.

[8] N. Kosinov, F. J. A. G. Coumans, G. Li, E. Uslamin, B. Mezari, A. S G. Wijpkema, E. A. Pidko, E. J. M. Hensen, J. Catal. 2017, 346, 125133.

[9] L. Liu, N. Wang, C. Zhu, X. Liu, Y. Zhu, P. Guo, L. Alfilfil, X. Dong, D. Zhang, Y. Han, Angew. Chemie - Int. Ed. 2019, 58, 2-9; Angew. Chem. 2020, 132, 829-835.

[10] N. Kosinov, F. J. A. G. Coumans, E. A. Uslamin, A. S. G. Wijpkema B. Mezari, E. J. M. Hensen, ACS Catal. 2017, 7, 520-529.

[11] N. Kosinov, A. S. G. Wijpkema, E. Uslamin, R. Rohling, F. J. A. G. Coumans, B. Mezari, A. Parastaev, A. S. Poryvaev, M. V. Fedin, E. A. Pidko, et al., Angew. Chemie - Int. Ed. 2018, 57, 1016-1020; Angew. Chem. 2018, 130, 1028-1032.

[12] I. Vollmer, B. Van Der Linden, S. Ould-Chikh, A. Aguilar-Tapia, I. Yarulina, E. Abou-Hamad, Y. G. Sneider, A. I. Olivos Suarez, J. L. Hazemann, F. Kapteijn, et al., Chem. Sci. 2018, 9, 4801-4807.

[13] M. Agote-Arán, A. B. Kroner, H. U. Islam, W. A. Sławiński, D. S. Wragg, I. Lezcano-González, A. M. Beale, ChemCatChem 2019, 11, 473-480.

[14] G. Li, I. Vollmer, C. Liu, J. Gascon, E. A. Pidko, ACS Catal. 2019, 9, 8731-8737.

[15] I. Vollmer, N. Kosinov, Á. Szécsényi, G. Li, I. Yarulina, E. AbouHamad, A. Gurinov, S. Ould-Chikh, A. Aguilar-Tapia, J. L. Hazemann, et al., J. Catal. 2019, 370, 321-331.

[16] Y. Xu, S. Liu, X. Guo, L. Wang, M. Xie, Catal. Letters 1994, 30, 135 149.

[17] L. Y. Chen, L. Lin, Z. Xu, X. Li, T. Zhang, J. Catal. 1995, 157, 190200.

[18] D. Wang, J. H. Lunsford, M. P. Rosynek, Top. Catal. 1996, 3, 289 297.

[19] F. Solymosi, J. Cserényi, A. Szöke, T. Bánsági, A. Oszkó, J. Catal. 1997, 165, 150-161.

[20] Y. Shu, Y. Xu, S. T. Wong, L. Wang, X. Guo, J. Catal. 1997, 170, $11-$ 19.

[21] S. Liu, L. Wang, R. Ohnishi, M. Ichikawa, J. Catal. 1999, 181, 175188.

[22] P. Mériaudeau, L. V. Tiep, V. T. T. Ha, C. Naccache, G. Szabo, J. Mol. Catal. A Chem. 1999, 144, 469-471.

[23] V. T. T. Ha, L. V. Tiep, P. Meriaudeau, C. Naccache, J. Mol. Catal. A Chem. 2002, 181, 283-290.

[24] I. Vollmer, S. Ould-Chikh, A. Aguilar-Tapia, G. Li, E. A. Pidko, J.-L. Hazemann, F. Kapteijn, J. Gascon, J. Am. Chem. Soc. 2019, 141,
18814-18824.

[25] I. Vollmer, E. Abou-Hamad, J. Gascon, F. Kapteijn, ChemCatChem 2019, 1-7.

[26] A. Pines, M. G. Gibby, J. S. Waugh, J. Chem. Phys. 1973, 59, 569590.

[27] G. A. Morris, R. Freeman, J. Am. Chem. Soc. 1979, 101, 760-762.

[28] A. D. Chowdhury, K. Houben, G. T. Whiting, M. Mokhtar, A. M. Asiri, S. A. Al-Thabaiti, S. N. Basahel, M. Baldus, B. M. Weckhuysen, Angew. Chem. Int. Ed. 2016, 55, 15840-15845; Angew. Chem. 2016, 128, 16072-16077.

[29] A. D. Chowdhury, A. L. Paioni, K. Houben, G. T. Whiting, M. Baldus, B. M. Weckhuysen, Angew. Chem. Int. Ed. 2018, 57, 8095-8099 Angew. Chem. 2018, 130, 8227-8231.

[30] A. D. Chowdhury, K. Houben, G. T. Whiting, S.-H. Chung, M. Baldus, B. M. Weckhuysen, Nat. Catal. 2018, 1, 23-31.

[31] O. C. Andronesi, S. Becker, K. Seidel, H. Heise, A. Howard S. Young, Marc Baldus, J. Am. Chem. Soc. 2005, 127, 12965-12974.

[32] A. A. Labokha, S. Gradmann, S. Frey, B. B. Hülsmann, H. Urlaub, M. Baldus, D. Görlich, EMBO J. 2012, 32, 204-218.

[33] A. A. Gabrienko, S. S. Arzumanov, A. V. Toktarev, I. G. Danilova, I. P. Prosvirin, V. V. Kriventsov, V. I. Zaikovskii, D. Freude, A. G. Stepanov, ACS Catal. 2017, 7, 1818-1830.

[34] M. V. Luzgin, A. V. Toktarev, V. N. Parmon, A. G. Stepanov, J. Phys. Chem. C 2013, 117, 22867-22873.

[35] K. Chakarova, N. Drenchev, K. Hadjiivanov, J. Phys. Chem. C 2012 116, 17101-17109

[36] R. Z. Khaliullin, A. T. Bell, V. B. Kazansky, J. Phys. Chem. A 2001, 105, 10454-10461.

[37] G. M. Bowers, H. T. Schaef, Q. R. S. Miller, E. D. Walter, S. D. Burton, D. W. Hoyt, J. A. Horner, J. S. Loring, B. P. McGrail, R. J. Kirkpatrick ACS Earth Sp. Chem. 2019, 3, 324-328.

[38] G. Englert, Zeitschrift für Naturforsch. A 1972, 27, 1536-1537.

[39] O. Olsvik, F. Billaud, J. Anal. Appl. Pyrolysis 1993, 25, 395-405

[40] E. A. Piocos, D. W. Werst, A. D. Trifunac, L. A. Eriksson, J. Phys Chem. 1996, 100, 8408-8417.

[41] A. Dutta Chowdhury, I. Yarulina, E. Abou-Hamad, A. Gurinov, J. Gascon, Chem. Sci. 2019, DOI 10.1039/C9SC02215E.

[42] A. Comas-Vives, M. Valla, C. Copéret, P. Sautet, ACS Cent. Sci. 2015, 1, 313-319.

[43] T. Maihom, M. Probst, J. Limtrakul, ChemPhysChem 2015, 16, 3334 3339.

[44] J. Guan, G. Yang, D. Zhou, W. Zhang, X. Liu, X. Han, X. Bao, J. Mol. Catal. A Chem. 2009, 300, 41-47.

[45] J. Handzlik, J. Mol. Catal. A Chem. 2010, 316, 106-111.

[46] Y. Jiang, M. Hunger, W. Wang, J. Am. Chem. Soc. 2006, 128, 1167911692.

[47] P. Cheung, A. Bhan, G. J. Sunley, E. Iglesia, Angew. Chemie - Int Ed. 2006, 45, 1617-1620; Angew. Chem. 2006, 118, 1647 -1650.

[48] X. Wang, G. Qi, J. Xu, B. Li, C. Wang, F. Deng, Angew. Chemie - Int Ed. 2012, 51, 3850-3853; Angew. Chem. 2012, 124, 3916- 3919.

[49] I. Lezcano-González, J. A. Vidal-Moya, M. Boronat, T. Blasco, A. Corma, Angew. Chemie - Int. Ed. 2013, 52, 5138-5141; Angew. Chem. 2013, 125, $5242-5245$.

[50] F. E. Celik, T. J. Kim, A. T. Bell, J. Catal. 2010, 270, 185-195.

[51] M. Lusardi, T. T. Chen, M. Kale, J. H. Kang, M. Neurock, M. E. Davis ACS Catal. 2020, 10, 842-851.

[52] D. Zhou, S. Zuo, S. Xing, J. Phys. Chem. C 2012, 116, 4060-4070.

[53] M. Siaj, H. Oudghiri-Hassani, C. Maltais, P. H. McBreen, J. Phys. Chem. C 2007, 111, 1725-1732.

[54] P. N. Plessow, F. Studt, ACS Catal. 2017, 7, 7987-7994.

[55] B. J. Dennis-Smither, Z. Yang, C. Buda, X. Liu, N. Sainty, X. Tan, G. J. Sunley, Chem. Commun. 2019, 55, 13804-13807.

[56] A. G. Stepanov, M. V. Luzgin, V. N. Romannikov, K. I. Zamaraev, J. Am. Chem. Soc. 1995, 117, 3615-3616.

[57] D. Rojo-Gama, M. Nielsen, D. S. Wragg, M. Dyballa, J. Holzinger, H. Falsig, L. F. Lundegaard, P. Beato, R. Y. Brogaard, K. P. Lillerud, et al., ACS Catal. 2017, 7, 8235-8246. 
WILEY-VCH

\section{Entry for the Table of Contents}

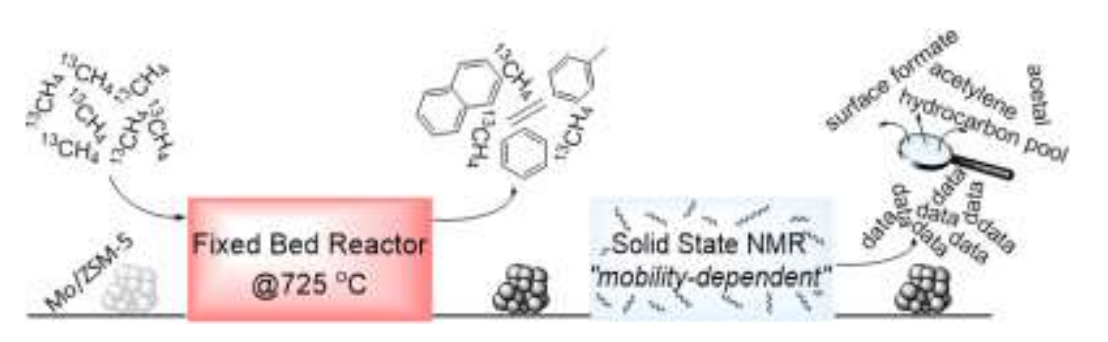

The initial carbon-carbon (C-C) bond formation during the early stages of methane dehydroaromatization was investigated by employing 'mobility-dependent' solid-state NMR. Based on the detected species (like acetylene, acetal etc.); two different mechanisms (monofunctional vs bi-functional) to the formation of direct C-C bonds were identified. 